Send your letters to the Editor, British Dental Journal, 64 Wimpole Street, London W1G 8YS E-mailbdj@bda-dentistry.org.uk

Priority will be given to letters less than 500 words long. Authors must sign the letter, which may be edited for reasons of space.

\section{The Unfair Playing Field}

Sir, - We are writing to you expressing our dismay that the GDC still appear to be dragging their heels with regard to the very advantaged position the Bodies Corporate find themselves compared to other dental practices. The tax rules that the Bodies Corporate work under gives the owners of these Bodies distinct advantages not enjoyed by the vast majority of dentists.

If it is unfair for a practice to survive the competition of a local drop-in-centre, that does not need to be concerned about financial viability, it is surely just as unfair to have the average practice pay far more tax than the branded practice down the road.

Tax on dividends paid by bodies corporate is currently 10\%. Compare this to the $41 \%$ paid by the vast majority of their competition and it soon becomes obvious how uneven the playing field is.

The big difference is that the GDC cannot influence the Government's view of drop-in centres but it does have the ability to bring every one under the same tax rules and give us all a level pitch to compete on.

When will our representatives start waking up to the 21st century and lets us run our practices as limited companies giving every one the same playing field to perform on?

\section{R. Ballard}

J. S. Tucker

Biggleswade

\section{Antony Townsend, Chief Executive and Registrar of the General Dental Council responds:}

The GDC is not dragging its heels: it has pressed for, and fully supports, the Department of Health's initiative to lift the ban in the Dentists Act which restricts corporate dentistry to the 27 existing Dental Bodies Corporate. The current situation distorts the market in dental companies and limits options for dentists to invest in practice development.

The Council has publicly supported the removal of the ban, most recently in its response to the Department of Health's recent consultation on this issue.

You can access the GDC's response at http://www.gdc-uk.org/Bods_Corp.html
The GDC now awaits the outcome of the Government consultation on the lifting of the ban.

The GDC has no power to lift the ban, but will work with the Government to try to ensure that the amending legislation is passed by Parliament as soon as possible.

\section{Mistaken identity}

Sir, - I am reluctant to add to your burdens but I must insist that a serious error has been allowed to permeate the hallowed columns of the BDJ letter pages. You published a letter from Mr. J. A. Quant who was a student at Guy's Hospital Dental School during the years that I studied there. However he was never one of my patients and he most certainly was not my Newland Pedley patient.

I was honoured with the award of the Newland Pedley Medal and Prize in 1955 and I clearly recall that my patient was a very charming young female dental student. To set the record straight it is important to note that the events described by Mr. Quant did not involve me but another recipient of the prize in a different year. Please call upon the guilty party to own up!

\section{B. Rothschild}

London

\section{Coronary symptoms}

Sir, - I am writing in memory of a good family friend who recently passed away at a young age from a heart attack and whose main presenting symptom was pain in the lower jaw on the left hand side. I would like to remind colleagues of symptoms of acute coronary syndromes.

Relief of pain in the face and jaw regions is one of the reasons for patients visiting a dentist for help. Dental problems, such as pulpitis and periapical periodontitis, are commonly the most obvious and identifiable causes of such pain. However, it is always wise to consider other less obvious sources which may lead to pain in the face and jaw regions.

Myocardial infarction is usually associated with constricting or crushing pains in the chest. In many cases this pain may radiate down the inside of the left arm or up into the neck or jaw. On rare occasions, the pain is felt in the jaw alone. ${ }^{1}$ Other symptoms such as dyspnoea, sweating and nausea are also commonly reported in addition to the presenting complaint of chest pain. ${ }^{2}$

A literature search of recent articles appears to suggest a gender difference in the presenting symptoms of acute coronary symptoms. Men were significantly less likely to complain of neck pain, back pain, jaw pain and nausea than women. Conversely, men were significantly more likely to report an increase in sweating than women. There were no statistically significant sex differences in complaints of chest pain though men were more likely to complain of this symptom. . $^{2,3,4}$

In addition, one paper appears to indicate a correlation between symptomatology and site of acute myocardial infarction. In particular, inferior infarctions were more often associated with epigastric, neck and jaw pain, sweating, nausea, vomiting, belching and hiccups. ${ }^{5}$

I hope this information may be of help to the profession and perhaps one day help save someone's life.

\section{G. A. Aristidou}

\section{London}

1. Cawson R A. Pain, anxiety and neurological disorders in Essentials of dental surgery and pathology. 5th ed. Edinburgh: Churchill Livingstone, 1991.

2. Bittner $V$ et al. Age and sex differences in presentation of symptoms among patients with acute coronary disease: the REACT Trial. Rapid Early Action for Coronary Treatment. Coron Artety Dis 2002; 11: 399407.

3. Bigelow $\mathrm{C}$ et al. Sex differences in symptom presentation associated with acute myocardial infarction: a population-based perspective. Am Heart J 1998; 136: 189-195.

4. Devon H A, Zerwic J J. Symptoms of acute coronary syndromes: are there gender differences? A review of the literature. Heart Lung 2002; 31: 235-245.

5. Culic $V$ et al. Correlation between symptomatology and site of acute myocardial infarction. Int J Cardiol 2001; 77: 163-168.

\section{Parental responsibility}

Sir, - The views expressed by N. Cole of Devon (BDJ 2002, 193:487-8) concern me as a responsible clinician. I quote from his letter, 'If $80 \%$ of those teeth were lost painlessly, 1 in 5 caused pain. It seems probable that nearly every one of those children whose carious teeth were not restored suffered pain. If I had been one of 
those parents, and had thought that my child had been looked after by a professional person whom I trusted, I would be pretty peeved to learn that my child's suffering had been caused by professional neglect'.

Dental caries is not caused by the dentist but in general by the choices made by the individual with regard to plaque control, fluorides and diet. Therefore any suffering experienced by the child as a result of dental caries must be the responsibility of the parent. Clearly the dentist must inform the parent of their responsibility in developing disease inactive oral environments in their child's mouth.

Informing patients requires dentists to assess patient groups in terms of their cultural norms and expectations. Communicating this message sympathetically is not easy.

Beal ${ }^{1}$ in the late 80 's wrote, 'All too often we end up with dentists seeking to transmit middle-class behaviour in middle-class terminology to workingclass people who speak another language. If the recipient of the message does not adopt the behaviour recommended by the dentist, he or she is then criticised as being apathetic, not caring about their teeth, or just plain "thick".

We accept the 80:20 rule (although now questioned by Tickle ${ }^{2}$ ) in that $80 \%$ of the disease is in $20 \%$ of the population, that $20 \%$ is mainly the socially disadvantaged. It is likely that the 1 in 5 children experiencing the pain will be from a deprived population.

Many adults learn through experience. In the context of communicating parental responsibility, what message are we communicating to a parent when we restore deciduous teeth in an oral cavity that is disease active? Are we saying (without words) that dental disease is inevitable? The population sub-group with most dental caries need to be praised for attending (even if the child is in pain) so that they re-attend. This gives valuable time so as to develop a dental career for the child, which is based on disease inactivity. The time frame required to influence behaviour change will vary according to the individual.

What I am not saying is that deciduous teeth in children should not be restored. What I am saying is that restorative dentistry in deciduous teeth should be in the context of disease inactive oral environments. This can only occur if we dentists communicate the reality of controllability of dental caries. Only then can parents be aware of their responsibility.

W. Richards
School of Care Sciences,

University of Glamorgan

1. Beal J F. Social factors and preventative dentistry. In Murray J J The Prevention of Dental Disease 2nd ed. Oxford University Press, 1989.

2. Tickle $\mathrm{M}$. The 80:20 phenomenon: help or hindrance to planning caries prevention programmes? Community Dent J 2002; 19: 39-42

\section{Panoramic radiography}

Sir, - We were surprised to put it mildly to see the letter (BDJ 2002; 193: 363) from M. Mupparapu of Philadelphia, USA. The letter describes two cases in which supernumerary molars were identified using panoramic radiography.

The author states that "cases like these, always remind us of the limitations of the intraoral radiographic examinations and the necessity for a more thorough examination of the jaws using the panoramic and/or other radiographic views'. The frequency of such supernumerary teeth ranges from 0.1 $1.0 \%$ of the population. Moreover, in the majority of cases, their presence in the jaws is utterly irrelevant to the patient's well being and their detection is highly unlikely to lead to any form of intervention.

It is interesting to see within the same edition of the $B D J$, two diametrically opposing philosophies of healthcare provision. The case report by Payne and colleagues outlining the use of panoramic radiography in the detection of Gardner's syndrome (BDJ 2002; 193: 383-4) states that 'it would be inappropriate to screen' every new patient with panoramic radiography for this condition'. If this is true for a life threatening condition like Gardner's syndrome, then surely it is true for patients with possible supernumerary teeth.

We, like Payne and colleagues, firmly support the cost-effective, individualised patient approach when using radiographic investigations based firmly upon the patient's clinical history and examination thereby prescribing radiographs for our patients, not passing them through a panoramic machine as routine.

V.E. Rushton

K. Horner

Manchester

\section{Dental student motivations}

Sir, - It was refreshing to see a direct comparison of the motivations of medical and dental students in the paper by Crossley and Mubarik (BDJ 2002; 193: 471 - 473). However, we would agree with $\mathrm{Mr}$ Grace (BDJ 2002;193: 485) that caution should be used when interpreting the results, before we write the profession off 
as insular and self centred.

Firstly, as the authors mention, a relatively small sample of students was used, and the wording of some of the questionnaire allowed for liberal interpretation.

We ought to be proud if students rank our professional status highly and consider dentistry to be a secure career, since both are positive attributes of the profession. It is worth noting that, in this study, three times as many medical as dental students agreed that they were influenced by their chosen profession's prestigious social standing, perhaps a less endearing determinant.

In addition, the relatively small proportion of dental students who cited altruistic motives for entering the profession differed from some existing published work, which showed these factors to have significantly influenced dental students on their choice of career. ${ }^{1,2}$

Different priorities have emerged from a number of papers regarding motivating factors for selecting a career in dentistry, so one must take care when trying to read too much into them.

\section{F. M. J. Stewart \\ J. R. Drummond \\ Dundee}

1. Gietzelt D. Social profile of first-year dentistry students at the University of Sydney. Aus Dent J 1997; 42: 259 - 266 .

2. Morris S. What kind of people want to become dentists? BDJ 1992; 173: 143 - 144.

\section{In-flight oral-facial pain}

Sir, - Ellingham's letter entitled 'Dentistry in the military' (BDJ 2002; 193:427-428) highlights dilemmas in advising pilots on flying after receiving dental treatment. Flight safety must always be the priority as any in-flight oral-facial pain may distract the pilot from flying or landing the aircraft and lead to a disaster.

Restorative treatment on a tooth may cause some inflammation of the pulp, resulting in barodontalgia as stated in the letter. It is for this reason that pilots are grounded for the rest of the day after restorative dental treatment with a local anaesthetic rather than because of local anaesthetic side effects.

Surgical emphysema may follow dental extractions but can occasionally follow routine dental treatment as stated by Chapman on the following page of the same edition of the $B D J$ (BDJ 2002; 193: 429). Another reason for grounding aircrew after dental extractions is that facial swelling can prevent fast jet and helicopter pilots wearing helmets comfortably.
As discussed in the letter, the main causes of in-flight oral-facial pain are barodontalgia and maxillary sinusitis. Nevertheless, diagnosis, especially in heavily restored dentitions, may be difficult. Tooth vitality testing, radiographs, sedative dressings and simulated flight in decompression chambers may all aid diagnosis. ${ }^{1}$ However, odd causes of oral-facial pain may not be amenable to conventional diagnostic procedures as illustrated by the following case:

A 30 year-old fast jet pilot complained of pain in his left cheek above altitudes of $20,000 \mathrm{ft}$. A deep restoration was noted in his upper left first molar and vitality testing was equivocal. He underwent a root canal treatment in the tooth but as his symptoms persisted, the tooth was extracted. His problems continued and after several courses of antibiotics for an assumed maxillary sinusitis he had a sinus washout under general anaesthetic. The symptoms of in-flight pain did not improve. A restoration in his upper second molar tooth was replaced but this did not help. The pilot then flew on a fast jet flight as a passenger to see if he could work out what was happening. At altitudes above 20,000 ft, he realised his flying helmet earphone on the left side was pressing into his cheek over the upper first molar area. Inspection of the earphone showed blockage of the hole that allows equalisation of pressures during ascent and descent. Expansion of air in the earphone at high altitude was not relieved by the hole. Following the fitting of a new earphone to his flying helmet he had no further problems with in-flight oral-facial pain.

Pressure from masks and earphones on the face may also dislodge partial dentures in flight and distract the pilot. Therefore, strong consideration should be given to providing fixed prosthesis for aircrew.

In-flight oral-facial pain can be a difficult problem. It is important to take as thorough and detailed a history as possible as well as keeping an open mind as to the diagnosis.

\section{A. J. Gibbons Birmingham}

1. Gibbons A J. Aviation Dentistry In Aviation Medicine and the Airline Passenger. 1st ed. Arnold: London, 2002 